\title{
Mucosal Fenestration After 2\% Chlorhexidine Extrusion Used in Substitution of Sodium Hypochlorite: A Case Report
}

\author{
Flávio Rodrigues Ferreira Alves ${ }^{1,2} \quad$ Marília F. Marceliano-Alves ${ }^{1} \quad$ Aline Carvalho de Souza ${ }^{3}$
} Andrea Fagundes Campello ${ }^{1}$

\author{
${ }^{1}$ Department of Endodontics, Iguaçu University, Nova Iguaçu, \\ Rio de Janeiro, Brazil \\ 2Post Graduation Program, Grande Rio University (UNIGRANRIO), \\ Duque de Caxias, Rio de Janeiro, Brasil \\ ${ }^{3}$ Brazilian Association of Dentistry, Niterói, Brazil
}

\begin{abstract}
Address for correspondence Marilia Fagury Videira MarcelianoAlves, PhD, Faculty of Dentistry, Iguaçu University, Av. Abílio Augusto Távora, 2134, Nova Iguaçu, Rio de Janeiro 26260-045, Brazil (e-mail: mmarceliano@hotmail.com).
\end{abstract}

Eur J Dent:2020;14:511-516

\begin{abstract}
Keywords

- chlorhexidine

- facial edema

- root canal irrigation

- root canal treatment

- sodium hypochlorite.

This report describes a case of sodium hypochlorite $(\mathrm{NaOCl})$ and chlorhexidine ( $\mathrm{CHX}$ ) extrusion through the apical foramen, causing acute pain, swelling and mucosal fenestration. A 62-year-old woman was referred for endodontic treatment in the first left maxillary premolar with a diagnosis of necrotic pulp. After the root canal irrigation with $2.5 \% \mathrm{NaOCl}$, the patient felt a burning sensation and pain. Discrete swelling and redness were noted in the patient's face at the end of the session. Antibiotic and corticosteroids were prescribed. In the next appointment, $2 \% \mathrm{CHX}$ was used, but another episode of extrusion occurred, with a sudden acute pain and intense swelling within a few minutes after the injection. After 2 weeks, the patient exhibited a left-side facial swelling extending anterior and inferior to the left zygomatic arch and superior to the body of the mandible. Oral antibiotic and anti-inflammatory drugs were administered. After 10 days, the swelling had completely diminished, but a mucosal fenestration and tooth mobility were verified. A cone beam CT was requested and showed a periapical lesion involving both buccal and palatal roots. After a prosthetic evaluation, the tooth extraction was indicated. One week after tooth removal, the mucosa was completely healed.
\end{abstract}

\section{Introduction}

The cleaning and disinfection of the root canals are paramount to the success of endodontic treatment, and these goals are achieved with the aid of irrigant solutions. Sodium hypochlorite $(\mathrm{NaOCl})$ is the most widely used intracanal irrigant because of its high-antimicrobial activity and necrotic tissue dissolution capacity. ${ }^{1-3}$ Notwithstanding this potential in striking the intracanal infection, $\mathrm{NaOCl}$ is dangerous to vital tissues, ${ }^{4}$ and care should be taken to maintain this substance restricted to the root canal.

The frequency of $\mathrm{NaOCl}$ extrusion during endodontic treatment is unknown. Although some authors believe that such accidents are rare, ${ }^{5-7}$ they are more frequent than expected, as reported in a recent systematic review covering six prestigious dentistry journals, including three exclusively dedicated to endodontics. ${ }^{8}$ That study presented a total of 231 cases of accidents related to the extrusion of $\mathrm{NaOCl}$ with a considerable number requiring hospitalization and a long time for regression of signs. Besides, it is expected that many cases of accidents with $\mathrm{NaOCl}$ are not reported. Therefore, a much higher frequency should be thought out. Fortunately, serious sequelae appear to be rare.

Faced with an accident of $\mathrm{NaOCl}$ extrusion, a common practice among the endodontists is change this irrigant for the chlorhexidine (CHX), since many studies reported its satisfactory antimicrobial activity, similar to $\mathrm{NaOCl},{ }^{9,10}$ and acceptable biocompatibility. ${ }^{11,12}$ However, some studies have 
questioned the safety of $\mathrm{CHX}$ when in contact with human tissues because even in concentrations lower or equal to $2 \%$, the CHX demonstrates toxicity to different cells types, including stem cells of the apical papilla, ${ }^{13,14}$ osteoblasts, ${ }^{15}$ and fibroblasts. ${ }^{16,17}$ Additionally, some previous studies reported serious complications after accidental injection of CHX into soft tissues or blood vessels. ${ }^{18-20}$

This report describes a case in which $\mathrm{NaOCl}$ was extruded through the apical foramen, causing acute pain and swelling. In the next session, $\mathrm{CHX}$ was used as alternative irrigant but produced an accident even more severe, with the occurrence of mucosal fenestration.

\section{Case Report}

A 62-year-old woman was referred to an endodontist by her clinician. The details given by the referring clinician included a history of pulp necrosis in the first left maxillary premolar, which had a fractured coronal amalgam restoration, deep caries, and radiographic signs of proximity with the pulp chamber. The patient reported a little discomfort with the mastication initiated 1 week early.

The clinical diagnosis of pulp necrosis was confirmed by the endodontist with cold and heat tests. There was no evidence of periapical lesion in the periapical radiograph (image not available because periapical radiographs were lost by the patient) and in the panoramic obtained before the session (-Fig. 1A). The initial interview with the patient revealed a past of good health and no significant medical history. With regard to the dental conditions, the patient presented some coronal restorations with resin and amalgam, absence of some permanent teeth, previous root canal treatments, and advanced resorption of alveolar bony crests in many teeth. However, the clinical examination confirmed that the periodontal condition was controlled because no calculus was verified. The patient also confirmed the absence of recent episodes of gum bleeding. Additionally, no drug allergies were reported.

The root canal treatment was initiated under local anesthesia with prilocaine $3 \%$ com felypressin $0.03 \mathrm{UI} / \mathrm{m}$. The treatment was started by caries and temporary restoration removal, followed by the exploration of the root canal with a $15 \mathrm{~K}$-file type instrument. During the root canal preparation, the root canal was irrigated with $\mathrm{NaOCl}$, which was delivered by a syringe and an open-ended flat needle with $0.55 \mathrm{~mm}$ of diameter (Becton Dickinson; Curitiba, PR, Brazil). The sequence of the root canal preparation included the following steps in Gates-Glidden burs II, III and IV were used to prepare the coronal two-thirds of the root canals in the radiograph tooth length subtracted of $5 \mathrm{~mm}, 7 \mathrm{~mm}$, and $9 \mathrm{~mm}$, respectively; exploration with a $15 \mathrm{~K}$-file type instrument and radiography for canal length measurement; and apical preparation with hand nickel-titanium files (Nitiflex; DentsplyMaillefer, Ballaigues, Switzerland) at the working length ( $1 \mathrm{~mm}$ short of the root apex), using a back-andforth alternated rotation motion. The apical preparation was beginning with the instrument size 20. Then, the instruments size 25 and 30 were used in sequence. Among each Gates-Glidden and file size incrementation, the canal was irrigated with $\mathrm{NaOCl}$, and the apical patency was checked with a $15 \mathrm{~K}$-file type. The apical preparation was not completed because when the canal was irrigated, after the use of

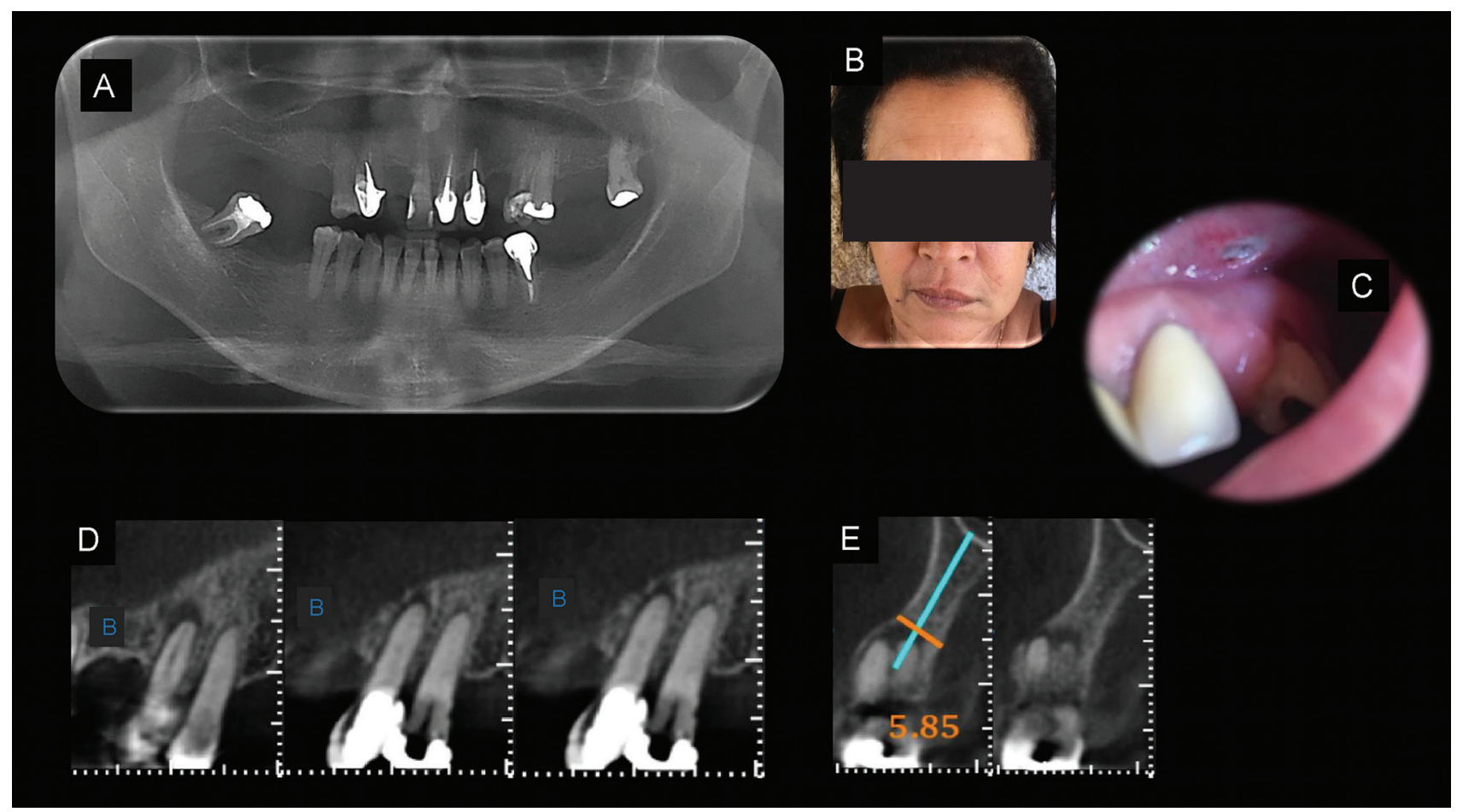

Fig. 1 (A) Panoramic radiograph. (B) Left-side facial swelling extending anterior and inferior to the left zygomatic arch and superior to the body of the mandible. (C) Mucosal fenestration. (D) Transversal sections in orthoradial view showing the periapical lesion. (E) Transversal sections in coronal view showing the periapical lesion involving both buccal and palatal roots. 
the size 30 instrument, the patient felt a sensation of burning and moderate pain. The session was interrupted by the suspicion of $\mathrm{NaOCl}$ extrusion, the root canal was irrigated with $20 \mathrm{~mL}$ of saline solution and the coronal cavity filled with Villevile (Dental Ville do Brasil LTDA, Nova Brasilia, Joinville, SC, Brazil). At the end of the session, a discrete swelling and redness were noted in the patient's face. Then, $100 \mathrm{mg}$ nimesulide was prescribed for 3 days. Asked by the professional, the patient emphasized that she had already made many contacts with sodium hypochlorite disinfectants used in domestic cleaning, without any further complications. The patient was oriented to return the communication in case of continuous pain. The next session was scheduled for 1 week later.

The patient reported no discomfort or swelling in the period between the first and second sessions. The second session was initiated with anesthesia using prilocaine $3 \% \mathrm{com}$ felypressin $0.03 \mathrm{UI} / \mathrm{m}$ and dental isolation with a rubber dam. Considering the previous occurrence of $\mathrm{NaOCl}$ extrusion, the irrigant chosen for the second session was 2\% CHX (Maquira, Maringá, PR, Brazil). According to the manufacturer, the solution composition included chlorhexidine digluconate, methylparaben, and purified water. Thereafter, the root canal was re-explored with a $15 \mathrm{~K}$ file-type instrument, and a radiograph was made to confirm the canal length. A few minutes after the continuing the root canal preparation, the patient experienced a sudden onset of acute pain and intense swelling in the tooth region. Immediately, the canal was irrigated with $20 \mathrm{~mL}$ of saline solution. A few minutes later, redness and warming were perceived on the skin adjacent to the tooth. The session was interrupted, and the root canal was filled with an intracanal medication with a calcium hydroxide paste and the coronal cavity sealed with Villevile (Dental Ville do Brazil LTDA). One hour after the session, the patient started the use of $600 \mathrm{mg}$ Ibuprofen in intervals of 6 hours, $500 \mathrm{mg}$ amoxicillin-clavulanic acid in intervals of 8 hours, and $0.75 \mathrm{mg}$ dexamethasone in intervals of 12 hours, following the endodontist's recommendations. The patient was oriented to return the communication in case of continuous pain. The treatment with the anti-inflammatories and the antibiotic were continued for 3 days and 7 days, respectively. After 2 weeks, the patient returned to the endodontist office for re-evaluation (third session). At that moment, the patient exhibited a left-side facial swelling extending anterior and inferior to the left zygomatic arch and superior to the body of the mandible ( $\boldsymbol{- F i g . ~ 1 B )}$ ). The facial and oral examinations revealed no evidence of trismus. The patient reported that the medications were effective in relieving the pain.

At the fourth session (10 days passed since the last), the swelling had diminished completely. However, the patient complained of a wound in her oral mucosa, near the affected tooth. The intraoral examination revealed a mucosal fenestration, measuring $4.5 \mathrm{~mm} \times 3.5 \mathrm{~mm}$, located anterior to the treated tooth and adjacent to its root apex ( - Fig. 1C). The lesion showed a circular shape and a discrete yellow color in the middle. The patient reported discomfort, bitter taste in her mouth, and abnormal tooth mobility, but no spontaneous or provoked pain, fever, or other symptoms were reported.
Next, the patient was referred to a maxillofacial surgeon for an evaluation. The patient was oriented by the surgeon to use mouthwash (Perioxidin, Laboratório Gross S/A, Rio de Janeiro, RJ, Brazil) for 2 weeks and to take $500 \mathrm{mg}$ amoxicillin-clavulanic acid in intervals of 8 hours for 7 days.

A cone beam CT was performed using an I-CT device (Imaging Sciences International, Hatfield, PA). Multiplanar reconstructions-axial, coronal and sagittal-and transversal sections with $1.0 \mathrm{~mm}$ thickness and $1.0 \mathrm{~mm}$ spacing were obtained. The cone beam CT showed a hypodense image, circumscribed by a hyperdense halo, in the periapical region of the first upper premolar associated with alveolar bone resorption, and involving both buccal and palatal roots. In addition, the coronal destruction becomes more evident in the cone beam CT images (-Figs. 1D and 1E).

The patient returned 4 months after that with no pain or swelling, but the mucosal fenestration was still present, measuring $1 \times 1 \mathrm{~mm}$. After a prosthetic evaluation, the tooth extraction was indicated. One week after the extraction, the mucosa was completely healed, with no more signs of fenestration. The follow-up was maintained for 1 year after the tooth extraction, and no alteration was noted in this period.

\section{Discussion}

The present report described a case of $\mathrm{NaOCl}$ and $\mathrm{CHX}$ extrusion in different moments with severe consequences that included acute pain, mobility, and mucosal fenestration. Even with a combined treatment with anti-inflammatories and antibiotic (to reduce the risk of secondary infection), the symptoms persisted by an extended period.

$\mathrm{NaOCl}$ is commonly used during root canal treatment, satisfying many requirements of an ideal irrigant: high efficiency against anaerobic and facultative microorganisms, dissolve and inactive endotoxin, and prevent or dissolve smear layer. ${ }^{21}$ However, the cytotoxic effects of $\mathrm{NaOCl}$ are the main concern regarding its use. When extruded, $\mathrm{NaOCl}$ causes the oxidization of the periradicular tissues, leading to immediately hemolysis and ulceration, facial nerve weakness and necrosis. ${ }^{22-24}$ In the cellular level, different effects include the neutrophil migration inhibition concomitant to endothelial cells death and fibroblast cells destruction. ${ }^{4}$

Accidents caused by the extrusion of $\mathrm{NaOCl}$ frequently produce acute pain with a sudden onset, even with the patient under the local anesthetics effect, and swelling. ${ }^{6}$ These effects happened after the first session of the present case. Previous studies reported hemorrhage through the root canal as a common occurrence in the case of $\mathrm{NaOCl}$ extrusion, ${ }^{25}$ but it was not observed in the present case. The main difference from the previous reports is that in the present one, CHX was also extruded in the following session. Apparently, this is the first case report of CHX extrusion. Although there is no previous report of extrusion of $\mathrm{CHX}$ solution beyond the apical foramen, this does not mean that it does not occur. The fact that the use of CHX as irrigant in endodontics is relatively recent, and this approach is restricted to some groups of clinicians, helps to understand why there is a lack of reports of 
CHX extrusion. Additionally, in the majority of the cases, CHX is used as a final irrigant and not as the main irrigant. ${ }^{26}$

Despite the toxicity of $\mathrm{NaOCl}$ and $\mathrm{CHX}$, there are many coadjutant factors related to the severity of the tissue damage, including (a) concentration, (b) volume, (c) pressure of extrusion, (d) proximity of the root apex with important anatomical structures, (e) thinness of cortical bone, (f) diameter of the apical foramen, $(\mathrm{g})$ periodontal conditions, (h) host allergy, and (i) retention time. ${ }^{8}$

The effect of $\mathrm{NaOCl}$ on bone tissue was evaluated in a study in which dog femurs were exposed to $\mathrm{NaOCl}$ for 30 minutes. Histological evaluations showed craters of demineralization, with remarkable degradation of the organic matrix collagen. ${ }^{27}$

The contact of $\mathrm{CHX}$ with bone also has the potential to produce tissue degradation. A previous study observed that cell death occurred within 2 minutes in cultures where osteoblasts were put in contact with $0.12 \%$ to $2 \% \mathrm{CHX} .{ }^{15} \mathrm{~A}$ different study showed that the osteoblast vitality was maintained when in a contact time of 5 minutes or more with CHX only with concentrations less than $0.002 \% .^{28}$ Evidence shows that CHX is also cytotoxic to fibroblasts because of inhibition of protein synthesis..$^{16,17}$

As far as the periodontal ligament cells are concerned, both $\mathrm{NaOCl}$ and $\mathrm{CHX}$ are cytotoxic in a concentration- and time-dependent manner. A study showed that $\mathrm{NaOCl}$ was cytotoxic to periodontal ligament cells at the concentrations of $0.025 \%$ or higher and CHX at $0.0001 \%$ or higher. When in the same concentration, CHX was significantly more cytotoxic to the periodontal ligament. ${ }^{16}$

The cytotoxicity effect of $\mathrm{NaOCl}$ and $\mathrm{CHX}$ on human cells is contact time-dependent. ${ }^{16,29}$ This variable is impossible to control in the clinic. When $\mathrm{NaOCl}$ is in the periradicular tissues, outside the root canal, the contact time will be finished only with the saturation of solution by the organic tissues. ${ }^{30}$ With the CHX, even appearing to be less aggressive than $\mathrm{NaOCl}$, since it is not solvent of organic tissues, longer contact time is expected because of its substantivity. ${ }^{31}$

In the present case, acute pain and swelling were observed with $\mathrm{NaOCl}$ extrusion, which was responsible for an initial chemical aggression. Probably, this first incident favored the occurrence of a more serious accident when the CHX was extruded, because some inflammation could be already present in the periradicular tissues. The accident could be even more severe if the root apex was closer to the maxillary sinus. Fortunately, almost $14 \mathrm{~mm}$ in distance separated the root apex from the maxillary sinus in a diagonal line, as measured in the cone beam (CT). The exact volume of extruded irrigants could not be measured, but according to the endodontist's impression, a 0.1 to $0.5 \mathrm{~mL}$ was extruded approximately in each episode. Furthermore, the pressure applied to the syringe plunger by the hand of the endodontist and retention time of contact between the irrigants and the periradicular tissues are difficult to estimate.

The present case was managed in an ambulatory manner, using only oral medications, including antibiotic, and a combination of nonsteroids and steroids anti-inflammatory drugs. This conduct is in accordance with the majority of the cases of $\mathrm{NaOCl}$ extrusion addressed in a recent systematic review. ${ }^{8}$ Besides, similar treatment was adopted in one case of accidental injection of $2 \%$ chlorhexidine gluconate instead of an anesthetic agent, which caused tissue necrosis. ${ }^{19}$

Ideally, root canal irrigants should be highly toxic for microorganism cells but not toxic for human cells. However, this is a form of utopia for $\mathrm{NaOCl}$ and $\mathrm{CHX}$. Taking into account the cytotoxic effects on the periradicular tissues, both $\mathrm{NaOCl}$ and $\mathrm{CHX}$ are unfavorable to the resolution of apical periodontitis when extruded through the apical foramen.

\section{Conclusion}

This case reported suggests that CHX should not be used as an alternative irrigant in cases of previous experience of $\mathrm{NaOCl}$ accident, because it has the potential to aggravate the tissue damage.

Funding

This study was supported by grants from Fundação Carlos Chagas Filho de Amparo à Pesquisa do Estado do Rio de Janeiro (FAPERJ), Brazilian Governmental Institution.

\section{Conflict of Interest}

None declared.

\section{References}

1 Siqueira JF Jr, da Silva CH, Cerqueira M das D, Lopes HP, de Uzeda M. Effectiveness of four chemical solutions in eliminating Bacillus subtilis spores on gutta-percha cones. Endod Dent Traumatol 1998;14(3):124-126

2 Zandi H, Rodrigues RC, Kristoffersen AK, et al. Antibacterial effectiveness of 2 root canal irrigants in root-filled teeth with infection: a randomized clinical trial. J Endod 2016;42(9):1307-1313

3 Zehnder M. Root canal irrigants. J Endod 2006;32(5):389-398

4 Pashley EL, Birdsong NL, Bowman K, Pashley DH. Cytotoxic effects of $\mathrm{NaOCl}$ on vital tissue. J Endod 1985;11(12):525-528

5 Khan S, Niu LN, Eid AA, et al. Periapical pressures developed by nonbinding irrigation needles at various irrigation delivery rates. J Endod 2013;39(4):529-533

6 Kleier DJ, Averbach RE, Mehdipour O. The sodium hypochlorite accident: experience of diplomates of the American Board of Endodontics. J Endod 2008;34(11):1346-1350

7 Spencer HR, Ike V, Brennan PA. Review: the use of sodium hypochlorite in endodontics-potential complications and their management. Br Dent J 2007;202(9):555-559

8 Guivarc'h M, Ordioni U, Ahmed HM, Cohen S, Catherine JH, Bukiet F. Sodium hypochlorite accident: a systematic review. J Endod 2017;43(1):16-24

9 Siqueira JF Jr, Rôças IN, Paiva SS, Guimarães-Pinto T, Magalhães KM, Lima KC. Bacteriologic investigation of the effects of sodium hypochlorite and chlorhexidine during the endodontic treatment of teeth with apical periodontitis. Oral Surg Oral Med Oral Pathol Oral Radiol Endod 2007;104(1):122-130

10 Rôças IN, Provenzano JC, Neves MA, Siqueira JF Jr. disinfecting effects of rotary instrumentation with either $2.5 \%$ sodium hypochlorite or $2 \%$ chlorhexidine as the main irrigant: a randomized clinical study. J Endod 2016;42(6):943-947

11 Vianna ME, Gomes BP, Berber VB. Zaia AA, Ferraz CC, de SouzaFilho FJ. In vitro evaluation of the antimicrobial activity of 
chlorhexidine and sodium hypochlorite. Oral Surg Oral Med Oral Pathol Oral Radiol Endod 2004;97(1):79-84

12 Mohammadi Z, Abbott PV. The properties and applications of chlorhexidine in endodontics. Int Endod J 2009;42(4):288-302

13 Widbiller M, Althumairy RI, Diogenes A. Direct and indirect effect of chlorhexidine on survival of stem cells from the apical papilla and its neutralization. J Endod 2019;45(2):156-160

14 Trevino EG, Patwardhan AN, Henry MA, et al. Effect of irrigants on the survival of human stem cells of the apical papilla in a platelet-rich plasma scaffold in human root tips. J Endod 2011;37(8):1109-1115

15 Bhandari M, Adili A, Schemitsch EH. The efficacy of low-pressure lavage with different irrigating solutions to remove adherent bacteria from bone. J Bone Joint Surg Am 2001;83(3): 412-419

16 Chang YC, Huang FM, Tai KW, Chou MY. The effect of sodium hypochlorite and chlorhexidine on cultured human periodontal ligament cells. Oral Surg Oral Med Oral Pathol Oral Radiol Endod 2001;92(4):446-450

17 Faria G, Celes MR, De Rossi A, Silva LA, Silva JS, Rossi MA. Evaluation of chlorhexidine toxicity injected in the paw of mice and added to cultured 1929 fibroblasts. J Endod 2007; 33(6):715-722

18 Ishigami S, Hase S, Nakashima H, et al. Intravenous chlorhexidine gluconate causing acute respiratory distress syndrome. J Toxicol Clin Toxicol 2001;39(1):77-80

19 Hiremath H, Agarwal RS, Patni P, Chauhan S. Accidental injection of $2 \%$ chlorhexidine gluconate instead of an anesthetic agent: A case report. J Conserv Dent 2016;19(1):106-108

20 Mohamed Iqbal I, Morris R, Hersch M. Adhesive arachnoiditis following inadvertent epidural injection of $2 \%$ chlorhexidine in $70 \%$ alcohol-partial recovery over the ensuing eight years. Anaesth Intensive Care 2018;46(6):572-574

21 Gonçalves LS, Rodrigues RC, Andrade Junior CV, Soares RG, Vettore MV.The effect of sodium hypochlorite and chlorhexidine as irrigant solutions for root canal disinfection: a systematic review of clinical trials. J Endod 2016;42(4):527-532

22 Witton R, Henthorn K, Ethunandan M, Harmer S, Brennan PA. Neurological complications following extrusion of sodium hypochlorite solution during root canal treatment. Int Endod J 2005;38(11):843-848

23 Gatot A, Arbelle J, Leiberman A, Yanai-Inbar I. Effects of sodium hypochlorite on soft tissues after its inadvertent injection beyond the root apex. J Endod 1991;17(11):573-574

24 Hülsmann M, Hahn W. Complications during root canal irrigation-literature review and case reports. Int Endod J 2000;33(3):186-193

25 Goswami M, Chhabra N, Kumar G, Verma M, Chhabra A. Sodium hypochlorite dental accidents. Paediatr Int Child Health 2014 34(1):66-69

26 Dutner J, Mines P, Anderson A. Irrigation trends among American Association of Endodontists members: a web-based survey. J Endod 2012;38(1):37-40

27 Kerbl FM, DeVilliers P, Litaker M, Eleazer PD. Physical effects of sodium hypochlorite on bone: an ex vivo study. J Endoc 2012;38(3):357-359

28 Patel P, Ide M, Coward P. Di Silvio L. The effect of a commercially available chlorhexidine mouthwash product on human osteoblast cells. Eur J Prosthodont Restor Dent 2006;14(2):67-72

29 Verdugo F, Castillo A, Moragues MD, Pontón J. Bone microbial contamination influences autogenous grafting in sinus augmentation. J Periodontol 2009;80(8):1355-1364

30 Dutta A, Saunders WP. Comparative evaluation of calcium hypochlorite and sodium hypochlorite on soft-tissue dissolution. J Endod 2012;38(10):1395-1398

31 Böttcher DE, Sehnem NT, Montagner F, Fatturi Parolo CC, Grecca FS. Evaluation of the effect of enterococcus faecalis biofilm on the $2 \%$ chlorhexidine substantivity: an in vitro study. J Endod 2015;41(8):1364-1370 